\title{
Modelo quantitativo para avaliação e melhoria de desempenho do processo de S\&OP baseado no diagnóstico e redução de falhas
}

\section{A quantitative model for the assessment and performance improvement of S\&OP process based on the diagnosis and reduction of failures}

\author{
Fabio José Pandim 1 \\ Néocles Alves Pereira1 \\ Paulo Rogério Politano ${ }^{2}$
}

\begin{abstract}
Resumo: O processo de Sales and Operations Planning - Planejamento de Vendas e Operações (S\&OP), assim como qualquer processo de nível estratégico ou tático, necessita ter o seu desempenho monitorado para que seja possível realizar ações de melhoria nos aspectos que estejam gerando impactos negativos em seu desempenho. Os modelos para análise de desempenho encontrados na literatura não trazem meios para localizar as causas de ineficiência mais relevantes, quando da utilização de processos S\&OP, bem como não fornecem uma maneira de se quantificar o desempenho do processo. Com o objetivo de contribuir com esta necessidade, o presente trabalho apresenta um modelo quantitativo para análise e melhoria de desempenho do processo de S\&OP baseado no diagnóstico e na redução de suas ineficiências mais importantes.
\end{abstract}

Palavras-chave: Planejamento de vendas e operações. Análise de desempenho. Fatores críticos de sucesso. Causas de ineficiência.

\begin{abstract}
The S\&OP process, like any business process of strategic or tactical level, requires having its performance measured so that, through the monitoring of these measurements, improvement actions for the factors affecting their performance can be created. The models for performance analysis in the literature failed to identify the most relevant causes of inefficiency to the process and do provide a way of measuring the process performance. Therefore, this paper presents a proposal for a quantitative model for the analysis and performance improvement of the $S \& O P$ process based on the diagnosis and reduction of its most important inefficiencies.
\end{abstract}

Keywords: Sales and operations planning. Performance analysis. Critical success factors. Causes of inefficiency.

\section{Introdução}

Em qualquer organização, as decisões de nível estratégico e tático relacionadas à capacidade produtiva geralmente estão vinculadas a uma incerteza considerável, pois objetivam o médio/longo prazo e envolvem recursos financeiros que não podem ser desprezados. Segundo Corrêa, Gianesi e Caon (2007), para que uma decisão deste tipo possa ser tomada, é necessário o desenvolvimento de uma certa "visão de futuro" que considere, dentro do horizonte de tempo associado, fatores como a demanda prevista e o nível de capacidade desejado.

Segundo Wallace (2001), uma das melhores soluções que visam prover esta "visão de futuro" é o processo de $\mathrm{S} \& \mathrm{OP}$, pois um de seus principais objetivos é buscar o balanceamento entre a demanda e a oferta de produtos, mostrando com antecedência, quando e onde as faltas e excessos de capacidade irão ocorrer.

Assim, ao investir na implantação de um processo como o de S\&OP, as organizações esperam que este seja executado de forma ininterrupta e que forneça informações confiáveis. Entretanto, falhas no processo podem ocorrer durante a sua realização, fazendo com que seus resultados não sejam satisfatórios e comprometam a tomada de decisões. Para minimizar estas falhas, pode ser muito interessante a utilização de

\footnotetext{
${ }^{1}$ Departamento de Engenharia de Produção - DEP, Universidade Federal de São Carlos - UFSCar, Rod. Washington Luís, Km 235, CEP 13565-905, São Carlos, SP, Brasil, e-mail: fabio@ pandin.com.br; neocles@ufscar.br

2 Departamento de Computação - DC, Universidade Federal de São Carlos - UFSCar, Rod. Washington Luís, Km 235, CEP 13565-905, São Carlos, SP, Brasil, e-mail: politanopr@yahoo.com.br
} 
um sistema de análise de desempenho que possibilite localizar e corrigir as causas de ineficiência mais importantes.

Entre os modelos encontrados na literatura que estabelecem escalas e categorias para avaliação do processo de S\&OP, destacam-se o modelo de maturidade do S\&OP de Lapide (2005) e o modelo de integração para o processo de S\&OP desenvolvido por Grimson e Pyke (2007). Entretanto, ambos utilizam categorias elaboradas de acordo com os objetivos dos seus modelos e não fica explícito nenhum grau intermediário de atendimento aos quesitos de classificação propostos. Além disso, não é explicado em que aspectos uma empresa precisa melhorar para ter um processo de S\&OP mais efetivo. A seção seguinte discute mais detalhadamente estas considerações.

Trata-se, portanto, da existência de um conjunto de deficiências que motivou a desenvolver um modelo quantitativo para avaliação e melhoria do processo de S\&OP baseado na identificação dos principais fatores críticos de sucesso do processo encontrados na literatura. Por meio da utilização deste modelo, uma empresa pode facilmente se posicionar dentro de uma escala de desempenho, a ser explicada, e identificar que ações adotar de forma a melhorar o desempenho do seu processo S\&OP. O modelo permite também quantificar o impacto de cada ação de melhoria no desempenho do processo S\&OP como um todo.

\section{$2 \mathrm{O}$ processo de $S \& O P$}

O processo de $\mathrm{S} \& O P$, de uma forma geral, pode ser definido como um processo de planejamento cíclico que busca, de forma consensual e em coerência com a estratégia da empresa, a tomada de decisões sobre capacidade, as quais focam o equilíbrio entre a demanda e a oferta de produtos dentro de um horizonte de tempo considerado. Isto é realizado por meio de reuniões periódicas multidisciplinares, o que facilita a integração entre as áreas funcionais da empresa na tomada de decisões.

Historicamente, o processo de $\mathrm{S} \& O P$ surgiu como um módulo estratégico do MRPII, visando o longo prazo e tendo como responsabilidade a criação de um plano agregado de produção e de vendas que satisfaça ao planejamento estratégico da organização.

Segundo Corrêa, Gianesi e Caon (2007), o processo de S\&OP também tem um papel muito importante no processo de gestão das organizações. Uma parte desta função é estabelecer uma integração vertical entre os níveis hierárquicos do planejamento, operando como um "tradutor" da estratégia organizacional para a estratégia operacional, de mais fácil compreensão para os níveis de decisão mais baixos. Outra parte se refere à integração horizontal, na qual, dentro de um mesmo nível hierárquico, o processo trabalha para que os diversos departamentos trabalhem juntos e direcionem seus esforços para que a estratégia organizacional seja alcançada.

Segundo Wallace (2001), além da integração vertical e horizontal proporcionada pelo processo de S\&OP nas organizações, ele também busca o balanceamento entre a demanda e a oferta dos produtos de uma empresa, procurando mostrar de maneira clara e com antecedência, quando e onde as faltas e excessos de capacidade produtiva irão ocorrer.

Segundo Elbaum (2005), S\&OP pode ser definido como um conjunto de processos de negócios e tecnologias que habilitam uma organização a efetivamente responder às variabilidades da demanda e suprimento com determinações antecipadas em seu mercado de atuação e sua cadeia de suprimentos, tudo dentro do horizonte de tempo determinado pelo S\&OP.

Já para Tearnan e Crum (2008), o processo de S\&OP consiste em uma série de passos em que várias organizações funcionais revisam o seu desempenho passado e seus planos futuros para desenvolverem uma visão integrada da demanda, suprimentos, desenvolvimento de novos produtos e resultados financeiros projetados em um horizonte de planejamento de até dois anos.

Sheldon (2006) define S\&OP como um planejamento cíclico mensal no qual planos para as expectativas dos clientes e operações internas são revisados em termos de precisão, responsabilidades, aprendizado e gerenciamento de risco futuro.

Alguns autores como Bremer et al. (2008a) e a Oliver Wight Americas (2009) destacam que o conceito moderno de $\mathrm{S} \& \mathrm{OP}$ envolve dois outros pontos que são muito relevantes atualmente:

As operações produtivas não são mais consideradas o gargalo do processo; hoje em dia, outros tipos de operações devem ser considerados, como Logísticas e Recursos Humanos. O envolvimento de outras áreas de negócio da empresa passa a ser fundamental para o bom funcionamento do processo;

O processo de $S \& O P$ passa a ser mais abrangente e extrapola os limites da empresa, envolvendo um forte relacionamento de colaboração com clientes e fornecedores com o objetivo de troca de informações sobre entregas, demandas, prazos e restrições, o que pode afetar as decisões estratégicas e operacionais.

Segundo Corrêa, Gianesi e Caon (2007), os quais adotam uma abordagem mais tradicional, o processo de S\&OP consiste de cinco etapas sucessivas, mostradas no Quadro 1.

Uma empresa que desenvolve o S\&OP repete estas cinco etapas diversas vezes ao longo do ano, isto é, o processo de $\mathrm{S} \& \mathrm{OP}$, por ser cíclico, deve ser repetido dentro de um período pré-determinado e possuir o mesmo horizonte de planejamento em cada ciclo de execução, como mostrado na Figura 1 (CORRÊA; GIANESI; CAON, 2007), na qual é possível observar 
que, enquanto um planejamento estratégico pode ser anual, o planejamento S\&OP pode ser visto como um processo praticamente contínuo, já que deve ser aplicado, por exemplo, mensalmente.

Na pesquisa denominada "O Retrato do Processo de S\&OP no Brasil" (BREMER et al., 2008b) respondida por mais de 90 empresas nacionais de diferentes portes, setores da economia e de diferentes posições dentro da sua cadeia de suprimentos, foi constatado que $77 \%$ dos respondentes utilizam o processo de S\&OP, ou seja, aproximadamente 69 empresas. Também foi identificado nesta pesquisa que aproximadamente $60 \%$ das empresas que possuem um processo de S\&OP implementado estão insatisfeitas com o desempenho do processo.

\section{Modelos para avaliação de desempenho do processo de S\&OP}

Nesta seção, são considerados os modelos mais citados na literatura acadêmica, discutidos e implementados por empresas de consultoria em supply chain e desenvolvidos pela organização mundial não lucrativa Supply Chain Council (SUPPLY CHAIN CONCIL, 2009), tanto de modelos de análise de desempenho específicos para o processo de S\&OP, bem como de modelos para análise de desempenho

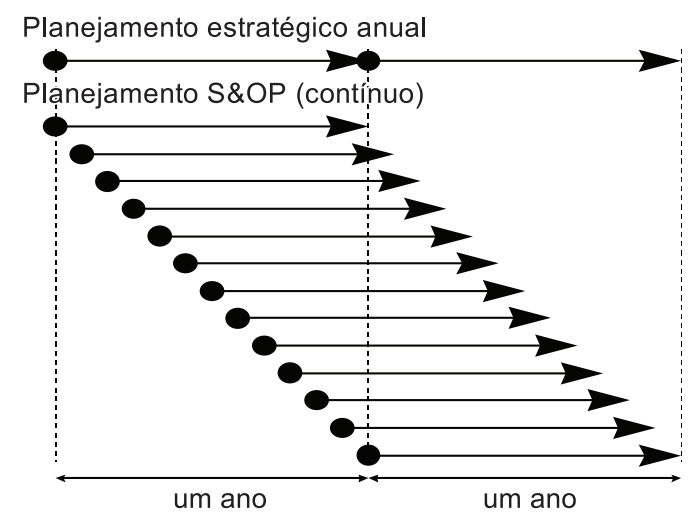

Figura 1. Ciclos periódicos e horizonte de planejamento. (CORRÊA; GIANESI; CAON, 2007). de processos em geral. Entre os específicos, destacam-se o modelo de maturidade de Lapide (2005) e o modelo de integração para o processo de S\&OP desenvolvido por Grimson e Pyke (2007), os quais se utilizam de categorias para pontuação em uma escala de maturidade. Entre os modelos que disponibilizam meios para a análise de processos em geral, destacam-se o modelo SCOR - Supply Chain Operations Reference Model (SUPPLY CHAIN CONCIL, 2009) e o modelo CHECKLIST - (OLIVER WIGHT AMERICAS, 2009), os quais apresentam sugestões de melhorias para ganhos de desempenho e possibilidade de comparação de resultados.

O modelo de maturidade do S\&OP criado por Lapide (2005) estabelece um conjunto de três categorias (Reuniões, Integração e Tecnologia) e quatro estágios de evolução (do mais simples ao mais avançado), mostrados no Quadro 2, em que é possível visualizar as características de cada estágio em cada categoria. Este modelo pretende auxiliar as empresas usuárias do S\&OP a modificarem os seus processos de negócio com os objetivos de: 1) aprimorar as suas execuções e a precisão dos planos desenvolvidos; e 2) determinar as tecnologias apropriadas e necessárias para suportar as mudanças ocasionadas pelos aprimoramentos inseridos no processo.

Segundo o autor, o modelo deve ser utilizado como uma ferramenta de diagnóstico para ajudar as empresas a melhorar seus processos de planejamento. Sua utilização contempla um conjunto de quatro passos:

1. Levantar as características do processo em uso dentro das categorias apresentadas;

2. Localizar o estágio correspondente de acordo com as características levantadas;

3. Identificar as falhas em seus processos que precisam ser melhoradas;

4. Propor as melhorias necessárias e analisar a viabilidade de implantação de cada uma delas.

Já Grimson e Pyke (2007), em seu modelo de integração do processo de $\mathrm{S} \& \mathrm{OP}$, cujo objetivo é

Quadro 1. Etapas do processo de S\&OP (CORRÊA; GIANESI; CAON, 2007).

\begin{tabular}{|c|l|}
\hline Etapa & \multicolumn{1}{|c|}{ Característica } \\
\hline Levantamento de Dados & $\begin{array}{l}\text { Informações sobre estoques, histórico de vendas, carteira de pedidos e entregas, por } \\
\text { família de produtos }\end{array}$ \\
\hline Planejamento de Demanda & $\begin{array}{l}\text { Previsão quantitativa e qualitativa realizada por meio da aplicação de modelos } \\
\text { matemáticos e julgamentos pessoais }\end{array}$ \\
\hline Planejamento da Produção & $\begin{array}{l}\text { Elaboração de cenários alternativos de planos de produção, suprimentos e financeiros } \\
\text { por meio da análise de suas restrições }\end{array}$ \\
\hline Reunião Preliminar & $\begin{array}{l}\text { Avaliação dos principais cenários desenvolvidos na etapa anterior e escolha de um para } \\
\text { ser viabilizado }\end{array}$ \\
\hline Reunião Executiva & $\begin{array}{l}\text { Análise e viabilização do cenário escolhido em relação ao planejamento estratégico da } \\
\text { organização e comunicação de decisões }\end{array}$ \\
\hline
\end{tabular}


Quadro 2. Modelo para avaliação da maturidade do processo de S\&OP (LAPIDE, 2005).

\begin{tabular}{|c|c|c|c|c|}
\hline & $\begin{array}{l}\text { Estágio } 1 \\
\text { Processo } \\
\text { marginal } \\
\end{array}$ & $\begin{array}{c}\text { Estágio } 2 \\
\text { Processo } \\
\text { rudimentar }\end{array}$ & $\begin{array}{c}\text { Estágio } 3 \\
\text { Processo } \\
\text { clássico } \\
\end{array}$ & $\begin{array}{c}\text { Estágio } 4 \\
\text { Processo } \\
\text { ideal } \\
\end{array}$ \\
\hline Reuniões & $\begin{array}{l}\text { Encontros } \\
\text { informais, } \\
\text { agendamentos } \\
\text { esporádicos. }\end{array}$ & $\begin{array}{l}\text { Encontros formais, } \\
\text { agendamentos } \\
\text { rotineiros, assiduidade } \\
\text { e participação } \\
\text { inconsistentes. }\end{array}$ & $\begin{array}{l}\text { Encontros formais com } \\
100 \% \text { de participação e } \\
\text { assiduidade. }\end{array}$ & $\begin{array}{l}\text { Encontros orientados a } \\
\text { eventos, agendamento } \\
\text { realizado quando } \\
\text { necessário, devido à } \\
\text { detecção de alguma } \\
\text { mudança ou algum } \\
\text { desbalanceamento entre a } \\
\text { demanda e suprimento. }\end{array}$ \\
\hline $\begin{array}{l}\text { Integração } \\
\text { do processo }\end{array}$ & $\begin{array}{l}\text { Processos } \\
\text { desarticulados com } \\
\text { planos separados. } \\
\text { Planos operacionais } \\
\text { não alinhados } \\
\text { com os planos de } \\
\text { demanda. }\end{array}$ & $\begin{array}{l}\text { Processos com alguma } \\
\text { integração. Planos } \\
\text { operacionais alinhados } \\
\text { com os planos de } \\
\text { demanda. }\end{array}$ & $\begin{array}{l}\text { Processos integrados. } \\
\text { Planos operacionais e } \\
\text { de demanda integrados. } \\
\text { Colaboração externa com } \\
\text { um pequeno número de } \\
\text { fornecedores e clientes. }\end{array}$ & $\begin{array}{l}\text { Processo estendido. Planos } \\
\text { operacionais e de demanda } \\
\text { alinhados internamente e } \\
\text { externamente. Colaboração } \\
\text { externa com a maioria dos } \\
\text { colaboradores e clientes. }\end{array}$ \\
\hline Tecnologia & $\begin{array}{l}\text { Mínima. Várias } \\
\text { planilhas eletrônicas } \\
\text { independentes. }\end{array}$ & $\begin{array}{l}\text { Aplicações } \\
\text { separadas. Sistema } \\
\text { de planejamento de } \\
\text { demanda, sistemas } \\
\text { APS individuais para } \\
\text { várias fábricas. }\end{array}$ & $\begin{array}{l}\text { Aplicações integradas. } \\
\text { Aplicações de } \\
\text { previsão de demanda } \\
\text { e planejamento de } \\
\text { operações integradas. } \\
\text { Informações externas } \\
\text { manualmente inseridas } \\
\text { no processo. }\end{array}$ & $\begin{array}{l}\text { Conjunto completo de } \\
\text { tecnologias integradas. } \\
\text { Sistema S\&OP específico } \\
\text { com um sistema de } \\
\text { colaboração externa } \\
\text { integrado aos sistemas } \\
\text { de previsão de demanda e } \\
\text { planejamento operacional. }\end{array}$ \\
\hline
\end{tabular}

a otimização dos lucros pela integração dos planos operacionais, contempla duas dimensões (processos organizacionais e processos de informação) as quais, juntas, são subdivididas em cinco categorias (Reuniões e Colaborações, Estrutura Organizacional, Médias de Desempenho, Tecnologia de Informação e Integração de Planos) e cinco estágios de evolução (do mais simples ao mais avançado), mostrados no Quadro 3. Sua utilização é similar ao modelo de Lapide (2005):

Como pode ser observado no quadro acima, o modelo de Grimson e Pyke (2007) abrange mais categorias para análise do processo e mais estágios de evolução do que o modelo de Lapide (2005), o que pode facilitar a uma empresa encontrar a localização do seu processo nos estágios.

Os modelos de Grimson e Pyke (2007) e Lapide (2005) não contemplam nenhum grau intermediário de atendimento às características propostas, o que pode contribuir para dificultar o posicionamento de uma empresa dentro das escalas. Por exemplo, se considerarmos o modelo de evolução de Lapide (2005), uma empresa que possua características avançadas para uma categoria, mas não o suficiente para evoluir para o próximo patamar, pode permanecer no mesmo estágio de uma outra empresa que possua uma versão bem mais básica das mesmas características.

Também é possível observar em ambos os modelos o fato de que, se uma empresa possuir características avançadas em uma categoria que a posicione em uma certa escala e características básicas em outras que a posicione em outra escala, não fica claro como classificar o processo desta empresa, já que nenhum deles estabelece níveis relativos de importância para as categorias. Ainda, se uma empresa desejar evoluir dentro das escalas, não fica claro em quais aspectos ou quanto estas precisam melhorar os seus processos.

O modelo SCOR (Supply Chain Operations Reference Model), ou modelo de referência das operações da cadeia de suprimentos, é um modelo de referência de processos de negócios desenvolvido pela Supply Chain Council (SCC). Este modelo de referência fornece um esquema único que faz a ligação entre processos de negócios, análise de desempenho, melhores práticas e uso de tecnologia em uma estrutura unificada que suporta a comunicação entre os parceiros da cadeia de suprimentos e melhora a efetividade das suas atividades e de seu gerenciamento (SUPPLY CHAIN CONCIL, 2009).

O seu funcionamento, segundo a Supply Chain Council (2009), é baseado na identificação, medição, reorganização e melhorias dos processos da cadeia de suprimentos. Isto é realizado por meio de um procedimento cíclico que envolve os seguintes passos:

- Obtenção da configuração da cadeia de suprimentos, a qual é baseada em cinco processos principais, mostrados no Quadro 4; 


\begin{tabular}{|c|c|c|c|c|c|}
\hline 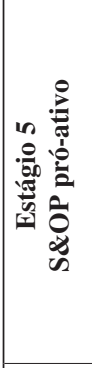 & 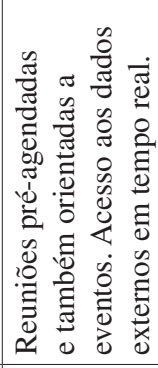 & 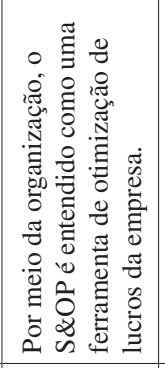 & 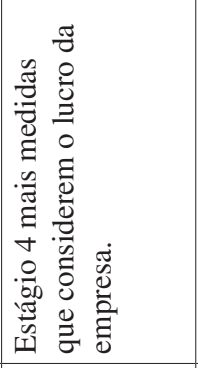 & 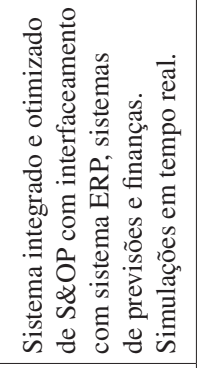 & 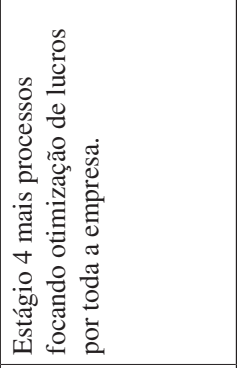 \\
\hline 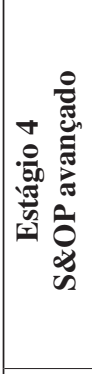 & 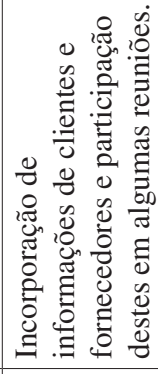 & 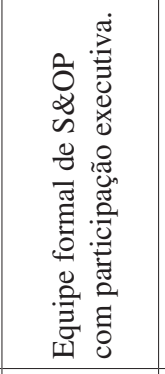 & 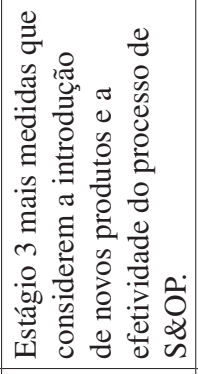 & 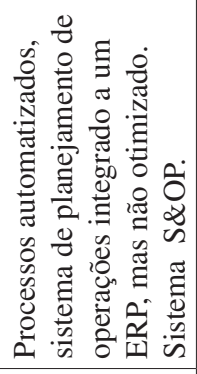 & 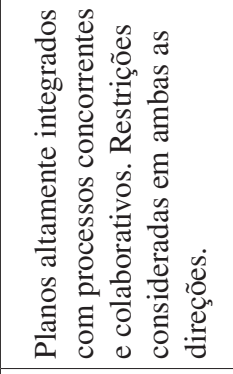 \\
\hline 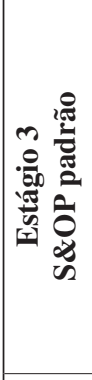 & 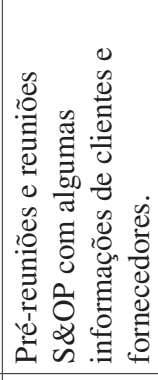 & 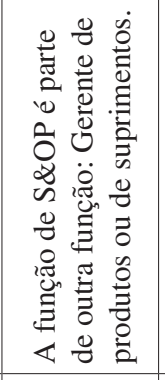 & 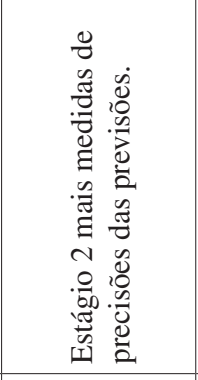 & 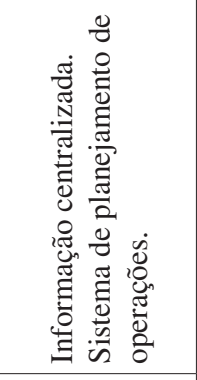 & 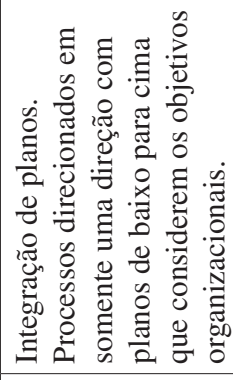 \\
\hline 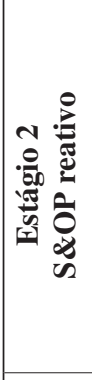 & 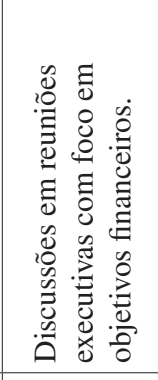 & 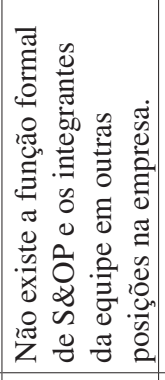 & 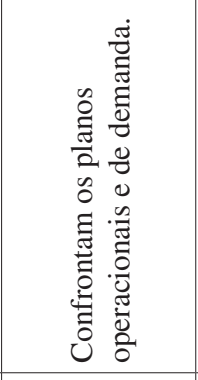 & 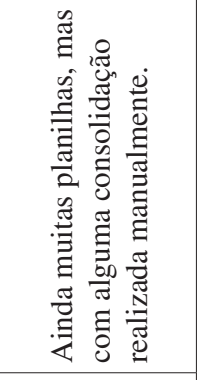 & 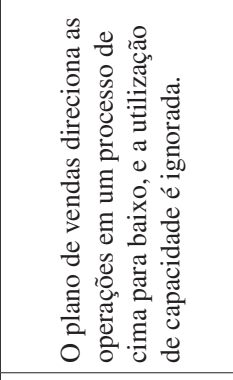 \\
\hline 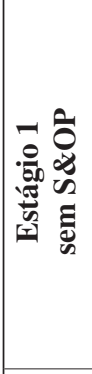 & 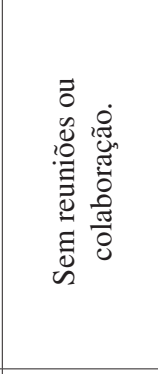 & 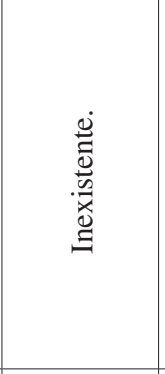 & 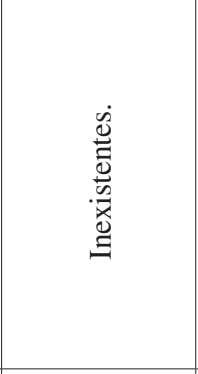 & 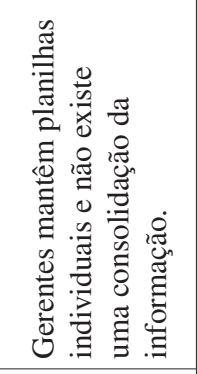 & 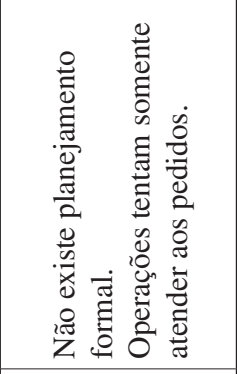 \\
\hline & 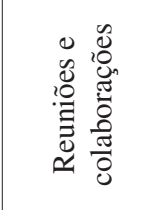 & 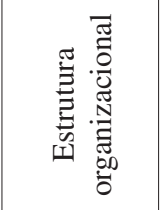 & 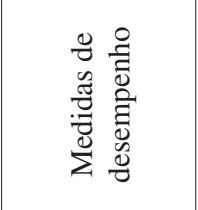 & 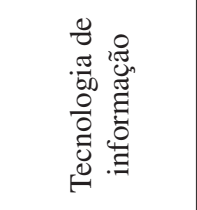 & 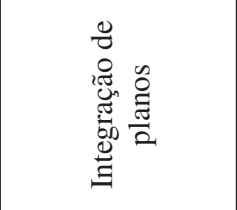 \\
\hline & \multicolumn{3}{|c|}{ 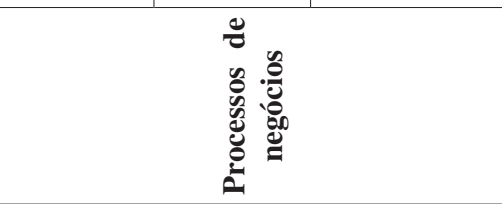 } & \multicolumn{2}{|c|}{ 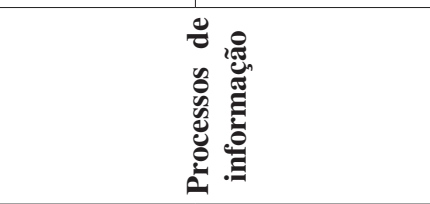 } \\
\hline
\end{tabular}


- Medição de desempenho da cadeia de suprimentos e comparação deste com os objetivos internos e externos da empresa;

- Realinhamento dos processos combinados com as melhores práticas da cadeia de suprimentos.

O método CHECKLIST, da Oliver Wight International, fornece uma abordagem para comparação do desempenho de uma empresa, assim como o SCOR, por meio da identificação das principais oportunidades de melhoria, as quais são levantadas por meio da aplicação de um conjunto abrangente de questões de avaliação, em que cada qual irá oferecer novas opções para explorar o modo como uma empresa pode melhorar sua posição competitiva e alcançar níveis de classe mundial de desempenho (OLIVER WIGHT AMERICAS, 2009). Para este conjunto de questões, estão disponíveis no Quadro 5 as opções de resposta e, por meio de uma média aritmética dos pontos obtidos em todas as questões, pode-se determinar em qual nível de desempenho a empresa se encontra, como mostrado no Quadro 6.

Segundo a Oliver Wight International (2000), os seguintes passos devem ser seguidos para se utilizar o CHECKLIST de maneira correta e alcançar sempre bons resultados tanto no curto quanto no longo prazo:

- Avaliação do status atual: Realizar o CHECKLIST somente nos processos que mais interessam o ganho de desempenho;

- Determinar as lacunas e priorizações baseados em vantagens competitivas: A diferença entre o desempenho de um processo em particular e seu desempenho máximo possível mostra a lacuna entre a empresa avaliada e as melhores práticas identificadas no CHECKLIST;

- Adequar a CHECKLIST às necessidades imediatas de sua empresa: A CHECKLIST deve ser adaptada a cada empresa para incorporar os termos mais comuns e estruturas hierárquicas;

- Desenvolver planos de ação: Os planos são atribuídos a pessoas responsáveis que devem executar suas atividades nos tempos determinados;

- Medir o progresso: Medir as pontuações ao longo do tempo, formando um histórico de informações que indica o progresso ou não das atividades;

Quadro 4. Processos principais do modelo SCOR (RODRIGUES et al., 2006).

\begin{tabular}{|c|l|}
\hline Processo & \multicolumn{1}{c|}{ Atividades } \\
\hline Planejar & $\begin{array}{l}\text { Definição de recursos e demanda, planejamento de estoques, distribuição, produção e planejamento de } \\
\text { capacidade em diversos níveis de agregação }\end{array}$ \\
\hline Abastecer & $\begin{array}{l}\text { Aquisição de matéria-prima, qualificação e certificação de fornecedores, monitorando qualidade, } \\
\text { negociação de contratos com vendedores e recebimento de materiais }\end{array}$ \\
\hline Fabricar & $\begin{array}{l}\text { Definição de métodos e locais de produção, testes, embalagens, mudanças nos processos, lançamentos } \\
\text { e apropriação de produtos }\end{array}$ \\
\hline Entregar & $\begin{array}{l}\text { Canais de entrega, localização dos estoques, gerenciamento do pedido e crédito, gerenciamento do } \\
\text { armazém, do transporte, da expedição e atendimento. Criação de base de dados dos consumidores, } \\
\text { produtos e preços }\end{array}$ \\
\hline Retornar & $\begin{array}{l}\text { Métodos de retorno da matéria-prima, produto acabado, manutenção, reparos e inspeção. Estes } \\
\text { processos estendem-se à pós-venda dando suporte ao consumidor }\end{array}$ \\
\hline
\end{tabular}

Quadro 5. Opções de resposta para o modelo CHECKLIST.

\begin{tabular}{|c|c|l|}
\hline Avaliação & Pontos & \multicolumn{1}{c|}{ Características } \\
\hline Excelente & 4 & Nível mais alto de resultados esperados desta atividade \\
\hline Muito bom & 3 & Atividade completamente executada cujos objetivos são atingidos \\
\hline Razoável & 2 & $\begin{array}{l}\text { Executa grande parte da atividade, ferramentas são utilizadas corretamente, mas não } \\
\text { completamente, não atingindo a totalidade dos resultados esperados }\end{array}$ \\
\hline $\begin{array}{c}\text { Inferior } \\
\begin{array}{c}\text { Não } \\
\text { realizado }\end{array}\end{array}$ & 1 & $\begin{array}{l}\text { Pessoas, processos e ferramentas não estão em seus níveis mínimos prescritos, resultando em } \\
\text { muito pouco benefício }\end{array}$ \\
\hline
\end{tabular}

Quadro 6. Nível de desempenho de acordo com o resultado do CHECKLIST.

\begin{tabular}{|c|c|c|c|c|}
\hline Pontuação média & De 0,00 a 1,49 & De 1,50 a 2,49 & De 2,50 a 3,49 & De 3,50 a 4,00 \\
\hline Nível & D & C & B & A \\
\hline
\end{tabular}


- Conduzir revisões gerenciais mensais: $\mathrm{O}$ propósito aqui é monitorar o progresso das atividades e observar os desvios destas dos objetivos.

Dentre os dois modelos gerais para análise de desempenho, o que mais se assemelha ao que será apresentado neste trabalho é o CHECKLIST, pois se utiliza de uma abordagem quantitativa devido à sua metodologia de pontuação por atividade do processo. Apesar destas semelhanças, este modelo não mostra automaticamente quais atividades merecem mais atenção, não contempla uma maneira de, enquanto se pontuam as atividades, estabelecer pesos de importância para cada uma delas e também não mostra as causas de ineficiência que podem levar ao não atingimento dos objetivos das atividades, fatores que serão abordados no modelo apresentado neste trabalho.

\section{Modelo para análise de desempenho do processo de S\&OP}

O modelo para análise de desempenho para o processo de S\&OP que este trabalho propõe é baseado na premissa de que o processo terá um bom desempenho se a empresa atender bem aos Fatores Críticos de Sucesso (FCS) mais relevantes relacionados ao processo. Segundo Pereira (2005), os FCS correspondem a um pequeno conjunto de tópicos estratégicos que necessariamente devem ser conduzidos corretamente para que os objetivos do processo de negócio ao qual eles são relacionados sejam atingidos. Ou seja, uma forma de se destacar o que realmente é relevante para os processos de negócio da empresa, permitindo desenvolver ações focadas mais eficazes para estes, maximizando o sucesso do processo.

Deste modo, o primeiro passo para a construção do modelo foi o levantamento, por meio de uma pesquisa bibliográfica, dos FCS relacionados ao processo de $\mathrm{S} \& O P$ e a identificação dos mais relevantes. Isto foi realizado pelo relacionamento destes FCS e da atribuição a cada um deles de um peso relativo de importância, dependendo do tipo de trabalho desenvolvido pelos autores sobre o processo de S\&OP: peso 1 para dissertação (identificado no Quadro 7 pela letra D); peso 2 para artigo ou periódico (identificado no Quadro 7 pela letra A); peso 3 para capítulo de livro (identificado no Quadro 7 pela letra C) e peso 4 para livro (identificado no Quadro 7 pela letra L).

A Tabela 1 mostra, na forma percentual, o grau de importância total de cada FCS encontrado na literatura. Para selecionar os FCS mais relevantes, serão considerados para serem incorporados ao modelo somente aqueles cujo percentual de importância acumulado atingiu até $80 \%$ do total. Desta forma, apenas os dez primeiros FCS listados na tabela serão considerados para serem utilizados no modelo.

O segundo passo da construção do modelo consiste em relacionar cada FCS selecionado a cada etapa do processo de S\&OP. Fazendo uma análise crítica, por meio da experiência profissional dos autores e da análise da literatura, entende-se que o relacionamento dos FCS com as etapas do processo de S\&OP pode ser construído como mostrado no Quadro 8.

Para exemplificar as relações definidas acima, vamos analisar o FCS "Apoio da alta administração". O relacionamento deste FCS foi realizado com as etapas "Reunião preliminar" e "Reunião executiva", pois são durante estas reuniões que ocorrem as principais tomadas de decisões do processo de S\&OP e, sem o apoio da alta administração, estas decisões podem não ser implementadas, comprometendo o desempenho do processo.

Os FCSs envolvidos na etapa de Planejamento da Produção do modelo proposto focam principalmente a área de manufatura, a qual diz respeito ao conceito tradicional de S\&OP para esta etapa. Apesar disto, os respondentes, se desejarem estender a análise, poderão incorporar novos FCSs relativos a outras áreas da empresa em qualquer etapa do processo.

Uma vez identificados os principais FCSs e a sua relação com as etapas do processo, o próximo passo constitui em identificar, para cada FCS de cada etapa, as possíveis causas de ineficiência (CI) responsáveis pelo seu não atendimento, como mostrado no Quadro 9, o qual mostra a identificação destas causas para os FCSs da etapa Planejamento da Produção.

Considerando, por exemplo, o FCS "Sistema informatizado de apoio", relativo à etapa "Planejamento da Produção", suas possíveis CIs foram relacionadas no Quadro 9, as quais fazem sentido, pois são causas relacionadas à ausência das principais características que deveriam fazer parte de qualquer sistema informatizado de apoio ao processo de S\&OP (WALLACE; STAHL, 2005). Seguindo esta lógica, o quadro acima foi desenvolvido. Em uma análise mais detalhada do quadro, pode-se observar as seguintes peculiaridades:

Uma mesma possível CI pode aparecer em mais de um FCS: a CI "Falta de conhecimentos sobre o processo de S\&OP pelos envolvidos" aparece em vários FCSs. Isto se deve ao fato de que é considerada uma CI de grande abrangência e que, portanto, possui impactos relevantes e diferentes nos FCSs e em diversas etapas;

FCSs iguais em etapas diferentes podem ter CIs diferentes: isto se deve ao fato de as CIs serem causadas principalmente por fatores humanos, já que as diferentes etapas do processo de S\&OP envolvem pessoas com níveis diferentes de qualificação; 


\begin{tabular}{|c|c|c|c|c|c|c|c|c|c|c|c|c|c|c|c|c|c|}
\hline 疋 & $\stackrel{0}{2}$ & $\Xi$ & 2 & $\mathcal{I}$ & $=$ & $=$ & 잉 & $r$ & 0 & 6 & 0 & in & $\nabla-$ & $\nabla \nabla$ & $m$ & $m$ & $N$ \\
\hline 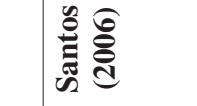 & $\varangle$ & & & $\varangle$ & & $\varangle$ & & & & & $\varangle$ & & & $\varangle<$ & $\varangle$ & & $\varangle$ \\
\hline 总 & $\varangle$ & & & $\varangle$ & & $\varangle$ & & & $\varangle$ & & & & $\varangle$ & & & & \\
\hline 造 & & & & $\varangle$ & & $\varangle$ & & & & & & & $\varangle$ & & & & \\
\hline 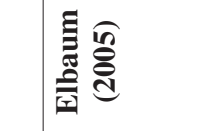 & $\varangle$ & $\varangle$ & & $\varangle$ & & & $\varangle$ & & & & & $\varangle$ & & & & & \\
\hline 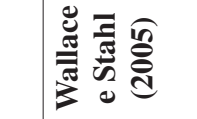 & & & & $\varangle$ & & & & & & & & & & 4 & & & \\
\hline ๘ & & • & & & & & & & & & & & & & & & \\
\hline 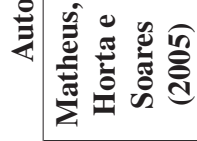 & $\varangle$ & $\varangle$ & $\varangle$ & $\varangle$ & & $\varangle$ & & & & $\varangle$ & & & & $\varangle$ & & & \\
\hline 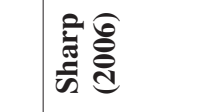 & & $\theta$ & & & & & a & & & & & & & & O & & \\
\hline 司 & & $\varangle$ & & & & & & & & & & & & & & & \\
\hline 黾高 & -1 & & - & & 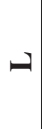 & & & & -1 & • & এ & & & & & & \\
\hline 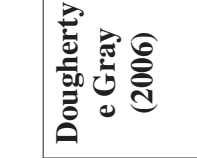 & -1 & & - & & -1 & & $\theta$ & - & & & & & & & & & \\
\hline 预焉 & & U & u & & U & U & u & u & & & & 0 & & & & u & \\
\hline 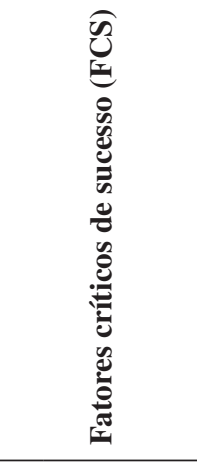 & 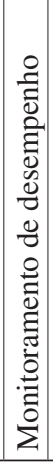 & 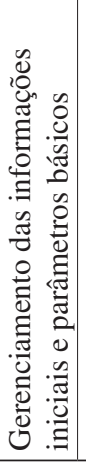 & 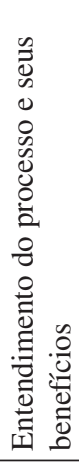 & 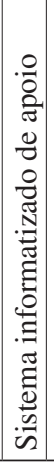 & 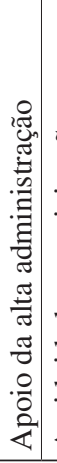 & 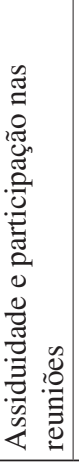 & 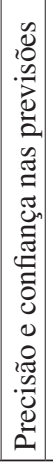 & 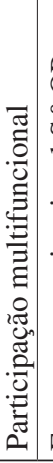 & 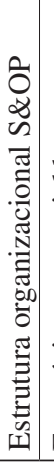 & 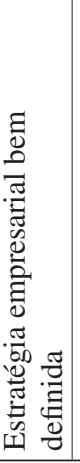 & 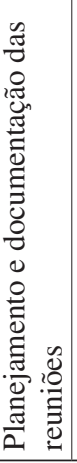 & 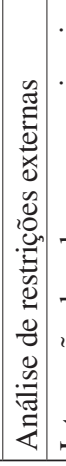 & 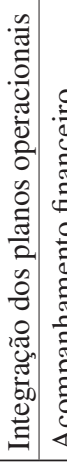 & 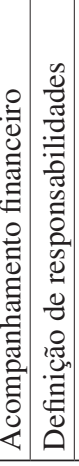 & 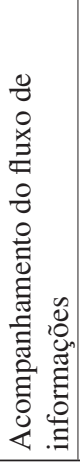 & 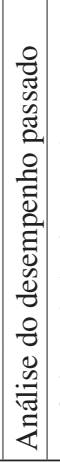 & 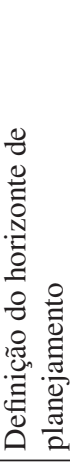 \\
\hline
\end{tabular}


Tabela 1. Seleção dos FCS.

\begin{tabular}{lccc}
\hline \multicolumn{1}{c}{ Fatores críticos de sucesso (FCS) } & Total & $\begin{array}{c}\text { (\%) de } \\
\text { importância }\end{array}$ & $\begin{array}{c}\text { (\%) de importância } \\
\text { acumulado }\end{array}$ \\
\hline Monitoramento de desempenho & 16 & 11,68 & 11,68 \\
Gerenciamento das informações iniciais e parâmetros básicos & 14 & 10,22 & 21,90 \\
Entendimento do processo e seus benefícios & 13 & 9,49 & 31,39 \\
Sistema informatizado de apoio & 12 & 8,76 & 40,15 \\
Assiduidade e participação nas reuniões & 11 & 8,03 & 48,18 \\
Apoio da Alta Administração & 11 & 8,03 & 56,20 \\
Precisão e confiança nas previsões & 10 & 7,30 & 63,50 \\
Participaçâo Multifuncional & 7 & 5,11 & 68,61 \\
Estratérgia empresarial bem definida & 6 & 4,38 & 72,99 \\
Planejamento e documentação das reuniões & 6 & 4,38 & 77,37 \\
Estrutura Organizacional S\&OP & 6 & 4,38 & 81,75 \\
Análise de restrições externas & 5 & 3,65 & 85,40 \\
Definição de responsabilidade & 4 & 2,92 & 88,32 \\
Integração dos Planos Operacionais & 4 & 2,92 & 91,24 \\
Acompanhamento financeiro & 4 & 2,92 & 94,16 \\
Análise do desempenho passado & 3 & 2,19 & 96,35 \\
Acompanhamento do fuxo de informações & 3 & 2,19 & 98,54 \\
Definição do horizonte de planejamento & 2 & 1,46 & 100,00 \\
\hline
\end{tabular}

Quadro 8. Relação dos principais FCS com as etapas do S\&OP.

\begin{tabular}{|l|c|c|c|c|c|}
\hline \multicolumn{1}{|c|}{$\begin{array}{c}\text { Fatores críticos de sucesso } \\
\text { selecionados }\end{array}$} & $\begin{array}{c}\text { Levantamento } \\
\text { de dados }\end{array}$ & $\begin{array}{c}\text { Planejamento } \\
\text { de demanda }\end{array}$ & $\begin{array}{c}\text { Planejamento } \\
\text { de produção }\end{array}$ & $\begin{array}{c}\text { Reunião } \\
\text { preliminar }\end{array}$ & $\begin{array}{c}\text { Reunião } \\
\text { executiva }\end{array}$ \\
\cline { 2 - 6 } Monitoramento de desempenho & $\mathbf{X}$ & $\mathbf{X}$ & $\mathbf{X}$ \\
\hline $\begin{array}{l}\text { Gerenciamento das informações } \\
\text { iniciais e parâmetros básicos }\end{array}$ & $\mathbf{X}$ & $\mathbf{X}$ & $\mathbf{X}$ & $\mathbf{X}$ & $\mathbf{X}$ \\
\hline $\begin{array}{l}\text { Entendimento do processo e seus } \\
\text { benefícios }\end{array}$ & $\mathbf{X}$ & $\mathbf{X}$ & $\mathbf{X}$ & $\mathbf{X}$ & $\mathbf{X}$ \\
\hline Sistema informatizado de apoio & & & $\mathbf{X}$ & $\mathbf{X}$ \\
\hline $\begin{array}{l}\text { Assiduidade e participação nas } \\
\text { reuniões }\end{array}$ & & & $\mathbf{X}$ & $\mathbf{X}$ & $\mathbf{X}$ \\
\hline Apoio da alta administração & & $\mathbf{X}$ & $\mathbf{X}$ & $\mathbf{X}$ & $\mathbf{X}$ \\
\hline Precisão e confiança nas previsões & & & $\mathbf{X}$ & $\mathbf{X}$ & $\mathbf{X}$ \\
\hline Participação multifuncional & & & $\mathbf{X}$ & $\mathbf{X}$ \\
\hline Estratégia empresarial bem definida & & & & \\
\hline $\begin{array}{l}\text { Planejamento e documentação das } \\
\text { reuniões }\end{array}$ & & & & \\
\hline
\end{tabular}

FCSs iguais em etapas diferentes podem ter CIs iguais: isto se deve ao fato de as CIs serem causadas principalmente por fatores organizacionais, os quais têm grande abrangência e podem influenciar o processo como um todo.

No passo a seguir, é sugerido, para cada CI de cada FCS, um conjunto de possíveis soluções (PS), as quais foram coletadas na literatura e também foram baseadas na experiência dos autores. As possíveis soluções estão divididas por etapa do processo de S\&OP e pode-se observar, no Quadro 10 , as que foram selecionadas para a etapa Planejamento da Produção.
Pode-se observar algumas peculiaridades no quadro acima:

- PSs iguais podem aparecer em CIs diferentes: Dependendo da PS, pode ter uma grande abrangência com diversos resultados. Estes resultados podem ser suficientes para reduzir ou eliminar, ao mesmo tempo, diversas CIs;

- PSs diferentes podem aparecer em CIs iguais: Dependendo da etapa do processo de S\&OP em que se encontrar a CI, as PSs serão diferentes, respeitando as particularidades de cada etapa do processo. 
Quadro 9. Possíveis CIs dos FCSs da etapa planejamento de produção (PANDIM, 2010).

\begin{tabular}{|c|c|c|}
\hline Etapa & Fator crítico de sucesso & Possíveis causas de ineficiência \\
\hline \multirow[t]{5}{*}{$\begin{array}{l}\text { Planejamento } \\
\text { da produção }\end{array}$} & $\begin{array}{l}\text { Monitoramento de } \\
\text { desempenho }\end{array}$ & $\begin{array}{l}1 \text { - Dificuldade de criação dos KPIs } \\
\text { (Indicadores-chave de desempenho) } \\
2 \text { - Não existe pessoal responsável por esta função }\end{array}$ \\
\hline & $\begin{array}{l}\text { Entendimento do } \\
\text { processo e seus } \\
\text { benefícios }\end{array}$ & $\begin{array}{l}1 \text { - Falta de conhecimentos sobre o processo de S\&OP pelos envolvidos } \\
2 \text { - Baixa qualificação profissional dos responsáveis por esta etapa }\end{array}$ \\
\hline & $\begin{array}{l}\text { Sistema informatizado } \\
\text { de apoio }\end{array}$ & $\begin{array}{l}1 \text { - O sistema informatizado de apoio não é integrado ao sistema de } \\
\text { gestão da empresa } \\
2 \text { - A interface não é adequada às necessidades desta etapa do processo } \\
3 \text { - O sistema informatizado de apoio não possibilita a construção de } \\
\text { cenários alternativos } \\
4 \text { - O sistema informatizado de apoio não possibilita a análise de } \\
\text { capacidade em tempo real }\end{array}$ \\
\hline & $\begin{array}{l}\text { Participação } \\
\text { multifuncional }\end{array}$ & $\begin{array}{l}1 \text { - Receio de se comprometer com decisões arriscadas } \\
2 \text { - Falta de apoio dos responsáveis pelos } \\
\text { departamentos funcionais } \\
3 \text { - Estrutura organizacional funcional } \\
\text { sem flexibilidade } \\
4 \text { - Falta de conhecimentos sobre o processo de S\&OP pelos envolvidos }\end{array}$ \\
\hline & $\begin{array}{l}\text { Estratégia empresarial } \\
\text { bem definida }\end{array}$ & $\begin{array}{l}1 \text { - A empresa não realiza um planejamento estratégico } \\
2 \text { - O planejamento estratégico contempla somente aspectos financeiros }\end{array}$ \\
\hline
\end{tabular}

Uma vez levantadas as informações iniciais necessárias, será explicado agora o funcionamento do modelo proposto para análise de desempenho do processo de S\&OP. Inicialmente deverão ser informados, para cada etapa do processo, pesos relativos de importância, os quais serão atribuídos de acordo com o julgamento pessoal do respondente.

Do mesmo modo, deverá ser atribuído para cada FCS relativo a cada etapa do processo, os quais foram levantados anteriormente, um peso indicando seu nível de importância em relação aos outros FCSs da etapa e uma nota de 0 a 10 , indicando o seu nível de atendimento pela empresa, ou seja, como o processo de S\&OP em funcionamento na empresa atende ao FCS, a nota 0 representará o não atendimento do FCS e a nota 10 o atendimento total.

Considerando os pesos relativos de cada FCS dentro da etapa e as notas representando os níveis de atendimento de cada FCS pelo processo de S\&OP na empresa, é possível calcular uma nota geral para a etapa em questão por meio da média ponderada entre os níveis de atendimento e dos pesos relativos da importância dos FCSs. Calculando-se esta nota para cada etapa do processo e considerando os pesos de importância de cada etapa, fornecidos no início, do mesmo modo também é possível calcular uma nota que representa o desempenho geral do processo de S\&OP na empresa, como mostrado no exemplo da Tabela 2.

Pode-se observar também que as notas das etapas do processo e a nota geral possuem uma cor associada.
Estas cores representam faixas de pontuação que indicam:

- Entre 0,00 e 2,49 - Vermelho - Processo insatisfatório;

- Entre 2,50 e 4,99 - Laranja - Processo regular;

- Entre 5,00 e 7,49 - Amarelo - Processo satisfatório;

- Entre 7,50 e 10,00 - Verde - Processo excelente.

Uma vez identificada a nota de cada etapa do processo e a sua nota geral, os passos a seguir terão como objetivo uma busca por um aumento de desempenho do processo e para isso deve-se encontrar qual etapa do processo pode contribuir ainda mais para o aumento da nota geral. Considerando ainda o exemplo da Tabela 2, tem-se uma nota geral do processo igual a 4,95 , isto significa que é possível ainda aumentar esta nota em 5,05 para a nota máxima ser atingida. Considerando esta nota complementar para atingir a nota máxima em cada FCS de cada etapa do processo, chega-se à Tabela 3, na qual se pode verificar que o FCS que mais tem a contribuir para a nota do processo como um todo é o FCS1 da Etapa 3.

Por meio destas informações, pode-se concluir que, para se aumentar o desempenho geral do processo, deve-se inicialmente priorizar os esforços para se melhorar o nível de contribuição do processo de S\&OP da empresa ao FCS1 da Etapa 3, o qual, se tiver uma melhora no seu nível de atendimento de 2 para 10 , aumentará a nota da etapa de 3,56 para 7,11 e a nota geral do processo de S\&OP de 4,95 para 5,74, 
Quadro 10. Possíveis soluções: Etapa 3 - planejamento da produção (PANDIM, 2010).

\begin{tabular}{|c|c|}
\hline \multicolumn{2}{|c|}{ FCS1: Monitoramento de desempenho } \\
\hline Causas de ineficiência & Possíveis soluções \\
\hline $\begin{array}{c}\text { CI1 - Dificuldade de criação dos KPIs } \\
\text { (Indicadores-chave de Desempenho) }\end{array}$ & $\begin{array}{l}\text { PS1 - Treinar as pessoas responsáveis na construção de KPIs para } \\
\text { esta etapa, como, por exemplo, a relação entre uma produção } \\
\text { programada e realizada e níveis de estoque }\end{array}$ \\
\hline $\begin{array}{c}\text { CI2 - Não existe pessoal responsável por esta } \\
\text { função }\end{array}$ & $\begin{array}{l}\text { PS1 - Atribuir esta função ao pessoal já existente, desde que } \\
\text { treinados, e cobrar resultados do monitoramento }\end{array}$ \\
\hline \multicolumn{2}{|c|}{ FCS2: Entendimento do processo e seus benefícios } \\
\hline Causas de ineficiência & Possíveis soluções \\
\hline $\begin{array}{l}\text { CI1 - Falta de conhecimentos sobre o } \\
\text { processo de S\&OP pelos envolvidos }\end{array}$ & $\begin{array}{l}\text { PS1 - Treinar as pessoas envolvidas nesta etapa sobre o processo de } \\
\text { S\&OP } \\
\text { PS2 - Explicar a importância que as funções desempenhadas pelas } \\
\text { pessoas nesta etapa têm no processo como um todo }\end{array}$ \\
\hline $\begin{array}{c}\text { CI2 - Baixa qualificação profissional dos } \\
\text { responsáveis por esta etapa }\end{array}$ & $\begin{array}{l}\text { PS1 - Treinar as pessoas envolvidas nesta etapa nos fundamentos } \\
\text { necessários } \\
\text { PS2 - Troca de pessoal }\end{array}$ \\
\hline \multicolumn{2}{|c|}{ FCS3: Sistema informatizado de apoio } \\
\hline Causas de ineficiência & Possíveis soluções \\
\hline $\begin{array}{l}\text { CI1 - O sistema informatizado de apoio não } \\
\text { é integrado ao sistema de gestão da empresa }\end{array}$ & $\begin{array}{l}\text { PS1 - Automatizar a transferência dos dados do sistema da empresa } \\
\text { para o sistema informatizado de apoio do S\&OP } \\
\text { PS2 - Considerar a troca do sistema informatizado de apoio }\end{array}$ \\
\hline $\begin{array}{c}\text { CI2 - A interface não é adequada às } \\
\text { necessidades desta etapa do processo }\end{array}$ & $\begin{array}{l}\text { PS1 - Se possível, customizar o sistema informatizado de apoio para } \\
\text { as necessidades desta etapa } \\
\text { PS2 - Considerar a troca do sistema informatizado de apoio }\end{array}$ \\
\hline $\begin{array}{c}\text { CI3 - O sistema informatizado de apoio } \\
\text { não possibilita a construção de cenários } \\
\text { alternativos }\end{array}$ & $\begin{array}{l}\text { PS1 - Analisar a possibilidade de se implementar esta função no } \\
\text { sistema. Se não for possível, considerar sua troca }\end{array}$ \\
\hline $\begin{array}{c}\text { CI4 - O sistema informatizado de apoio não } \\
\text { possibilita a análise de capacidade em tempo } \\
\text { real }\end{array} \mid$ & $\begin{array}{l}\text { PS1 - Analisar a possibilidade de se implementar esta função no } \\
\text { sistema. Se não for possível, considerar sua troca } \\
\text { PS2 - Integrar o sistema informatizado de apoio a um sistema que } \\
\text { tenha capacidade de APS (Advanced Planning and Scheduling), que } \\
\text { realiza cálculos que consideram capacidade finita } \\
\text { PS3 - Considerar a troca do sistema informatizado de apoio }\end{array}$ \\
\hline \multicolumn{2}{|c|}{ FCS4: Participação multifuncional } \\
\hline Causas de ineficiência & Possíveis soluções \\
\hline $\begin{array}{c}\text { CI1 - Receio de se comprometer com } \\
\text { decisões arriscadas }\end{array}$ & $\begin{array}{l}\text { PS1 - Conscientizar os envolvidos de que as decisões são tomadas } \\
\text { em conjunto, sob a responsabilidade de todos }\end{array}$ \\
\hline $\begin{array}{c}\text { CI2 - Falta de apoio dos responsáveis pelos } \\
\text { departamentos funcionais }\end{array}$ & $\begin{array}{l}\text { PS1 - Todos na empresa devem conhecer o processo de S\&OP e sua } \\
\text { importância. Os participantes devem ter autonomia suficiente para } \\
\text { priorizar o processo de S\&OP }\end{array}$ \\
\hline $\begin{array}{c}\text { CI3 - Estrutura organizacional funcional sem } \\
\text { flexibilidade }\end{array}$ & $\begin{array}{l}\text { PS1 - Com o apoio da alta administração, dar "carta branca" aos } \\
\text { envolvidos no processo de S\&OP para se dedicarem a ele quando } \\
\text { necessário }\end{array}$ \\
\hline $\begin{array}{c}\text { CI4 - Falta de conhecimentos sobre o } \\
\text { processo de S\&OP pelos envolvidos }\end{array}$ & $\begin{array}{l}\text { PS1 - Treinar as pessoas envolvidas nesta etapa sobre o processo de } \\
\text { S\&OP } \\
\text { PS2 - Explicar a importância que as funções desempenhadas pelas } \\
\text { pessoas nesta etapa têm no processo como um todo }\end{array}$ \\
\hline \multicolumn{2}{|c|}{ FCS5: Estratégia empresarial bem definida } \\
\hline Causas de ineficiência & Possíveis soluções \\
\hline $\begin{array}{c}\begin{array}{c}\text { CI1 - A empresa não realiza um planejamento } \\
\text { estratégico }\end{array} \\
\end{array}$ & $\begin{array}{l}\text { PS1 - Treinar a alta administração em planejamento estratégico por } \\
\text { meio da contratação de uma consultoria especializada no assunto }\end{array}$ \\
\hline $\begin{array}{c}\text { CI2 - O planejamento estratégico contempla } \\
\text { somente aspectos financeiros }\end{array}$ & $\begin{array}{l}\text { PS1 - Propor metodologias alternativas de planejamento estratégico, } \\
\text { como, por exemplo, o Balanced Scorecard, SWOT, uma combinação } \\
\text { das duas }\end{array}$ \\
\hline
\end{tabular}


Tabela 2. Modelo de análise de desempenho para o processo de S\&OP.

\begin{tabular}{|c|c|c|c|c|c|c|}
\hline \multicolumn{6}{|c|}{ Etapa 1 - Levantamento de dados } & \multirow{2}{*}{$\begin{array}{c}\text { Peso etapa: } 4 \\
\text { Contribuição } \\
(\%)\end{array}$} \\
\hline & Peso FCS & $\begin{array}{c}\text { Peso relativo } \\
(\%)\end{array}$ & $\begin{array}{c}\text { Atendimento do FCS } \\
\text { pelo S\&OP }\end{array}$ & Nota FCS & Falta p/ 10 & \\
\hline FCS1 & 1 & 20,00 & 8,0 & 1,60 & 0,40 & 8,33 \\
\hline FCS2 & 2 & 40,00 & 3,0 & 1,20 & 2,80 & 58,33 \\
\hline \multirow[t]{2}{*}{ FCS3 } & 2 & 40,00 & 6,0 & 2,40 & 1,60 & 33,33 \\
\hline & & 100,00 & Nota Etapa $1 \rightarrow$ & 5,20 & 4,80 & 100,00 \\
\hline \multicolumn{6}{|c|}{ Etapa 2 - Planejamento de demanda } & Peso etapa: 4 \\
\hline & Peso FCS & $\begin{array}{c}\text { Peso relativo } \\
(\%)\end{array}$ & $\begin{array}{c}\text { Atendimento do FCS } \\
\text { pelo S\&OP }\end{array}$ & Nota FCS & Falta p/ 10 & $\begin{array}{c}\text { Contribuição } \\
(\%)\end{array}$ \\
\hline FCS1 & 3 & 21,43 & 3,0 & 0,64 & 1,50 & 18,58 \\
\hline FCS2 & 2 & 14,29 & 3,0 & 0,43 & 1,00 & 12,39 \\
\hline FCS3 & 3 & 21,43 & 1,0 & 0,21 & 1,93 & 23,89 \\
\hline FCS4 & 3 & 21,43 & 2,0 & 0,43 & 1,71 & 21,24 \\
\hline \multirow[t]{2}{*}{ FCS5 } & 3 & 21,43 & 1,0 & 0,21 & 1,93 & 23,89 \\
\hline & & 100,00 & Nota Etapa $2 \rightarrow$ & 1,93 & 8,07 & 100,00 \\
\hline \multicolumn{6}{|c|}{ Etapa 3 - Planejamento da produção } & Peso etapa: 6 \\
\hline & Peso FCS & $\begin{array}{c}\text { Peso relativo } \\
(\%)\end{array}$ & $\begin{array}{c}\text { Atendimento do FCS } \\
\text { pelo S\&OP }\end{array}$ & Nota FCS & Falta p/ 10 & $\begin{array}{c}\text { Contribuição } \\
(\%)\end{array}$ \\
\hline FCS1 & 4 & 44,44 & 2,0 & 0,89 & 3,56 & 55,17 \\
\hline FCS2 & 1 & 11,11 & 2,0 & 0,22 & 0,89 & 13,79 \\
\hline FCS3 & 1 & 11,11 & 3,0 & 0,33 & 0,78 & 12,07 \\
\hline FCS4 & 1 & 11,11 & 5,0 & 0,53 & 0,56 & 8,62 \\
\hline \multirow[t]{2}{*}{ FCS5 } & 2 & 22,22 & 7,0 & 1,56 & 0,67 & 10,34 \\
\hline & & 100,00 & Nota Etapa $3 \rightarrow$ & 3,56 & 6,44 & 100,00 \\
\hline \multicolumn{6}{|c|}{ Etapa 4 - Reunião preliminar } & Peso etapa: 8 \\
\hline & Peso FCS & $\begin{array}{c}\text { Peso relativo } \\
(\%)\end{array}$ & $\begin{array}{c}\text { Atendimento do FCS } \\
\text { pelo S\&OP }\end{array}$ & Nota FCS & Falta p/ 10 & $\begin{array}{c}\text { Contribuição } \\
(\%)\end{array}$ \\
\hline FCS1 & 3 & 21,43 & 8,0 & 1,50 & 0,38 & \\
\hline FCS2 & 1 & 6,25 & 2,0 & 0,13 & 0,50 & \\
\hline FCS3 & 3 & 21,43 & 9,0 & 1,69 & 0,19 & \\
\hline FCS4 & 1 & 6,25 & 2,0 & 0,13 & 0,50 & \\
\hline FCS5 & 2 & 12,50 & 2,0 & 0,25 & 1,00 & \\
\hline FCS6 & 3 & 21,43 & 6,0 & 1,13 & 0,75 & \\
\hline FCS7 & 1 & 6,25 & 4,0 & 0,25 & 0,38 & \\
\hline \multirow[t]{4}{*}{ FCS8 } & 2 & 12,50 & 6,0 & 0,75 & 0,50 & \\
\hline & & 100,00 & Nota Etapa $4 \rightarrow$ & 5,81 & 4,19 & 100,00 \\
\hline & \multicolumn{4}{|c|}{ Etapa 5 - Reunião executiva } & & Peso etapa: 10 \\
\hline & Peso FCS & $\begin{array}{c}\text { Peso relativo } \\
(\%)\end{array}$ & $\begin{array}{c}\text { Atendimento do FCS } \\
\text { pelo S\&OP }\end{array}$ & Nota FCS & Falta $p / 10$ & $\begin{array}{c}\text { Contribuição } \\
(\%)\end{array}$ \\
\hline FCS1 & 3 & 21,43 & 10,0 & 2,14 & 0,00 & \\
\hline FCS2 & 3 & 21,43 & 8,0 & 1,71 & 0,43 & \\
\hline FCS3 & 2 & 14,29 & 8,0 & 1,14 & 0,29 & \\
\hline FCS4 & 1 & 7,14 & 3,0 & 0,21 & 0,50 & \\
\hline FCS5 & 3 & 21,43 & 8,0 & 1,71 & 0,43 & \\
\hline FCS6 & 1 & 7,14 & 1,0 & 0,07 & 0,64 & \\
\hline \multirow[t]{2}{*}{ FCS7 } & 1 & 7,14 & 1,0 & 0,07 & 0,64 & \\
\hline & & 100,00 & Nota Etapa $5 \rightarrow$ & 7,07 & 1,21 & 100,00 \\
\hline
\end{tabular}


fazendo com que o desempenho saia da faixa de pontuação laranja, considerada regular, e passe para a faixa amarela, considerada satisfatória.

Como foi verificado que se deve aumentar o nível de contribuição do processo de S\&OP da empresa ao FCS1 da Etapa 3, o modelo irá sugerir um conjunto

Tabela 3. Contribuição de cada FCS na nota geral do S\&OP.

\begin{tabular}{clccc}
\hline Etapa & FCS & Atendimento & $\begin{array}{c}\text { Nota } \\
\text { S\&OP }\end{array}$ & $\begin{array}{c}\text { Faltam 10 } \\
\text { S\&OP }\end{array}$ \\
\hline 3 & FCS1 & 2,0 & 0,20 & 0,79 \\
2 & FCS3 & 1,0 & 0,04 & 0,32 \\
2 & FCS5 & 1,0 & 0,04 & 0,32 \\
1 & FCS2 & 3,0 & 0,13 & 0,31 \\
2 & FCS4 & 2,0 & 0,07 & 0,29 \\
2 & FCS1 & 3,0 & 0,11 & 0,25 \\
4 & FCS5 & 2,0 & 0,06 & 0,22 \\
3 & FCS2 & 2,0 & 0,05 & 0,20 \\
5 & FCS6 & 1,0 & 0,02 & 0,18 \\
5 & FCS7 & 1,0 & 0,02 & 0,18 \\
1 & FCS3 & 6,0 & 0,27 & 0,18 \\
3 & FCS3 & 3,0 & 0,07 & 0,17 \\
4 & FCS6 & 6,0 & 0,25 & 0,17 \\
2 & FCS2 & 3,0 & 0,07 & 0,17 \\
3 & FCS5 & 7,0 & 0,35 & 0,15 \\
5 & FCS4 & 3,0 & 0,06 & 0,14 \\
3 & FCS4 & 5,0 & 0,12 & 0,12 \\
5 & FCS2 & 8,0 & 0,48 & 0,12 \\
5 & FCS5 & 8,0 & 0,48 & 0,12 \\
4 & FCS2 & 2,0 & 0,03 & 0,11 \\
4 & FCS8 & 6,0 & 0,17 & 0,11 \\
4 & FCS4 & 2,0 & 0,03 & 0,11 \\
4 & FCS1 & 8,0 & 0,33 & 0,08 \\
4 & FCS7 & 4,0 & 0,06 & 0,08 \\
5 & FCS3 & 8,0 & 0,32 & 0,08 \\
1 & FCS1 & 8,0 & 0,18 & 0,04 \\
4 & FCS3 & 9,0 & 0,38 & 0,04 \\
5 & FCS1 & 10,0 & 0,60 & 0,00 \\
\hline & Total & & 4,95 & 5,05 \\
\hline & & & &
\end{tabular}

de possíveis causas de ineficiência (CI) que estejam dificultando o aumento do nível de atendimento deste FCS. Os conjuntos pré-selecionados das possíveis CIs para cada FCS de cada etapa do processo podem ser visualizados no Quadro 9.

A seguir, o respondente deverá informar para cada CI relacionada ao FCS1 da Etapa 3 um peso relativo de importância e informar uma nota entre 0 e 10 que represente o grau de aderência (concordância ou não do respondente em relação às CIs relacionadas pelos autores com o FCS em questão) de cada possível CI ao FCS 1 - 0 para nenhuma aderência e 10 para aderência total, como pode-se observar no exemplo da Tabela 4.

Analisando o exemplo acima, pode-se encontrar a aderência relativa ao FCS1 da Etapa 3 de cada CI e, utilizando isto como um peso, pode-se calcular, por meio do uso de média ponderada, a contribuição negativa de cada CI ao FCS1 da Etapa 3. Para isso será assumido uma relação linear entre a redução e/ou a eliminação das CIs e o aumento do nível de contribuição do processo ao FCS considerado.

Continuando a análise da Tabela 4, observa-se que o nível de atendimento do processo de S\&OP da empresa ao FCS1 da Etapa 3 pode ser aumentado de 2,0 para 6,9 pela eliminação da CI1, cujo nível de contribuição negativa ao FCS1 atinge $60,87 \%$. Isto foi calculado multiplicando-se o valor 8 (complementar de 2 para 10 ) por $60,87 \%$, que resulta em 4,9 , que, somado aos 3 pontos iniciais, resulta em um nível de atendimento com 6,9 pontos. Este aumento do nível de contribuição do processo de S\&OP ao FCS1 da Etapa 3 também refletirá em um aumento da etapa 3, passando de 3,56 para 5,73, e também na nota final do processo de S\&OP, que passará de 4,95 para 5,43.

Identificada a $\mathrm{CI}$ mais relevante ao não atendimento do FCS1 da Etapa 3 do processo de S\&OP da empresa, o modelo irá então sugerir possíveis soluções (PS) para sua eliminação, as quais podem ser visualizadas no Quadro 10.

Deverá ser informado pelo respondente, para cada PS, um valor percentual indicando a sua probabilidade

Tabela 4. Aderência e Importância das CI's

\begin{tabular}{|c|c|c|c|c|}
\hline \multicolumn{5}{|l|}{ Etapa 3} \\
\hline \multicolumn{5}{|l|}{ FCS 1} \\
\hline Possíveis $\mathrm{Cl}^{\prime} \mathrm{s}$ & Peso & $\begin{array}{c}\text { Peso relativo } \\
(\%)\end{array}$ & Aderência ao FCS & $\begin{array}{c}\text { Aderência relativa } \\
(\%)\end{array}$ \\
\hline $\mathrm{Cl1}$ & 10,0 & 66,67 & 7,0 & 60,87 \\
\hline \multirow[t]{2}{*}{$\mathrm{Cl} 2$} & 5,0 & 33,33 & 9,0 & 39,13 \\
\hline & & 100,00 & & 100,00 \\
\hline Atendimento atual & 2,0 & & & \\
\hline $60,87 \%$ de $8(10-2)$ & 4,9 & & & \\
\hline Eliminando $\mathrm{Cl}+$ relevante & 6,9 & & & \\
\hline
\end{tabular}


Tabela 5. Sugestão de PS's à CI mais relevante.

Etapa 3
FCS 1
Cl 1

\begin{tabular}{|cccc|}
\hline Possíveis soluções & Probabilidade de sucesso & $\begin{array}{c}\text { Viabilidade de } \\
\text { implementação }\end{array}$ & $\begin{array}{c}\text { Viabilidade } \\
\text { revisada }\end{array}$ \\
\hline PS1 & $100,00 \%$ & $50,00 \%$ & $50,00 \%$ \\
PS2 & $60,00 \%$ & $90,00 \%$ & $54,00 \%$ \\
\hline
\end{tabular}

de sucesso na eliminação da CI1 e um valor percentual indicando a sua viabilidade de implementação. Entende-se como solução viável aquela que possui facilidade, rapidez e baixos custos envolvidos na sua implementação e entende-se por probabilidade de sucesso a chance da implementação da solução eliminar ou reduzir a CI correspondente. Multiplicando o percentual da probabilidade de sucesso pelo percentual de viabilidade de implementação, chega-se a um valor denominado "Viabilidade Revisada", a qual indicará qual PS deverá ser primeiro implementada pela empresa (Tabela 5).

No exemplo acima, conclui-se que a PS2, apesar de sua menor probabilidade de sucesso, será a PS selecionada como melhor candidata à implementação devido a sua maior viabilidade revisada. Novamente, propondo uma relação linear entre a PS selecionada e a eliminação da CI1, considera-se que a implementação da PS2 reduzirá os efeitos da CI1 em 60\%.

Como visto anteriormente, a eliminação total da CI1 representaria um aumento no nível de contribuição do processo de S\&OP da empresa ao FCS1 da etapa 3 em 4,9 pontos, mas isto só se ela fosse completamente eliminada. Como a implementação da PS2 possui uma chance de sucesso de $60 \%$, e considerando-se a linearização do relacionamento da PS com a CI, pode-se concluir que a sua implementação conseguirá aumentar o nível de contribuição do processo de S\&OP ao FCS1 da Etapa 3 em $60 \%$ de 4,9 (o que resulta em 2,9), fazendo com que o nível de contribuição ao FCS1 da Etapa 3 passe de 2 para 4,9, a nota da Etapa 3 passe de 3,56 para 4,84 e a nota geral do processo aumente de 4,95 para 5,23.

Ainda existe a possibilidade de o respondente desejar implementar mais de uma possível solução, o que resultaria em uma alteração no cálculo da chance de sucesso total. Por exemplo, se duas possíveis soluções, cada uma com uma chance de sucesso de $50 \%$, fossem implementadas em conjunto, a chance de sucesso total poderia ser calculada como $50 \%$ da primeira mais $50 \%$ da segunda, o que resultaria em um valor de $75 \%$.

\section{Conclusões}

Os modelos de análise de desempenho encontrados na literatura estão mais voltados à realização de uma análise macro e qualitativa do processo, fornecendo modelos de referência que devem ser seguidos para que as empresas possam se enquadrar em uma ou outra categoria de avaliação. Dentre os que foram apresentados, o que mais adere ao modelo proposto neste trabalho foi o método do CHECKLIST, da Oliver Wight International, pois se utiliza de uma abordagem quantitativa que utiliza uma forma de pontuação por atividade do processo.

Apesar desta aderência, o CHECKLIST não mostra as atividades que merecem destaque, não contempla uma maneira de, enquanto se pontuam as atividades, estabelecer relações de importância para cada uma delas e também não mostra as causas de ineficiências que podem levar ao não atendimento dos objetivos das atividades, fatores que foram abordados no modelo apresentado neste trabalho.

Já o modelo proposto permite quantificar o desempenho do processo de S\&OP e também mostra, de acordo com as notas e pesos informados, em qual etapa e em qual FCS focar as ações de melhorias, sugerindo soluções para a causa de ineficiência mais relevante, de modo que seja possível visualizar o incremento da pontuação do processo em sua empresa.

Analisando o funcionamento do modelo, é possível observar que ele também possibilita uma análise de sensibilidade, pois a redução ou eliminação de uma CI associada a um FCS de uma etapa pode ter resultados ou não no mesmo FCS em outras etapas, dependendo do tipo de PS adotada e do tipo da CI. Por exemplo, o FCS "Sistema informatizado de apoio" possui, em algumas etapas, a CI "O sistema informatizado de apoio não é integrado ao sistema de gestão da empresa". Possíveis soluções que reduzissem ou eliminassem esta CI poderiam ter efeitos nesta mesma CI associada a FCS em outras etapas, já que esta CI pode ser causada por fatores tecnológicos e podem ter abrangência por toda a organização.

Outro fator a ser analisado é que, durante o preenchimento do modelo, existe a possibilidade de se adicionar um novo FCS que ela considere importante, associá-lo a algumas etapas do processo de S\&OP, incluir novas CIs para este novo FCS ou para FCSs já existentes e ainda incluir sugestões de PS para as novas CIs ou CIs já existentes. Desta maneira, estes novos FCS, CIs e PS poderiam aperfeiçoar o modelo e o seu funcionamento. 
Devido também ao tipo de disponibilização do modelo, ele deverá permitir, respeitando a privacidade das empresas, que a média de desempenho do processo de S\&OP de todas as empresas de um mesmo ramo de atividade e faixa de tamanho possa ser visualizada por uma empresa respondente, de modo que esta possa, como uma forma de benchmark, comparar o desempenho do seu processo ao de outras empresas do mesmo ramo e tamanho que o seu.

Pode-se destacar ainda, a importância do modelo apresentado como sendo um modelo original de avaliação de desempenho e diagnóstico do processo de $S \& O P$ e que fornece as receitas/ações priorizadas para a redução de falhas do processo, não tendo similares na literatura.

\section{Referências}

BREMER, C. F.; AZEVEDO, C. R.; MATHEUS, L. F. O Retrato do Processo de Sales \& Operations Planning (S\&OP) no Brasil - Parte 1. Revista Mundo Logística, n. 5, p. 68, 2008a.

BREMER, C. F.; AZEVEDO, C. R.; MATHEUS, L. F. O Retrato do Processo de Sales \& Operations Planning (S\&OP) no Brasil - Parte 2. Revista Mundo Logística, n. 6, p. 10, 2008b.

CORRÊA, H. L.; GIANESI, I. G. N.; CAON, M. Planejamento, Programação e Controle da Produção. 5. ed. São Paulo: Atlas, 2007.

DOUGHERTY, J. R.; GRAY, C. D. Sales and operations planning: best practices - lessons learned from worldwide companies. Trafford on Demand Pub, 2006.

ELBAUM, S. Best Practices in S\&OP: A Benchmark Report. Aberdeen Group, 2005. Disponível em: <www. aberdeen.com>. Acesso em: jun. 2005.

GRIMSON, J. A.; PYKE, D. F. Sales and Operations Planning: an exploratory study and framework. The International Journal of Logistics Management, v. 18 , n. 3 , p. 322-346, 2007. http://dx.doi. org/10.1108/09574090710835093

LAPIDE, L. Sales and operations planning part iii: a diagnostic model. The Journal of Business Forecasting, v. 24, n. 1, p. 13-16, 2005.

MATHEUS, L. F.; HORTA, L. C.; SOARES, H. B. Proposição de ações estratégicas para superação das barreiras e efetiva implantação do processo de planejamento integrado (S\&OP). In: ENCONTRO NACIONAL DE ENGENHARIA DE PRODUÇÃO, 25., 2005, Porto Alegre. Anais... Porto Alegre, 2005.

OLIVER WIGHT AMERICAS. The Oliver Wight ABCD Checklist for Operational Excellence. Disponível em: $<$ http://www.oliverwight-americas.com/ow_library/ cklst_5.htm>. Acesso em: dez. 2009.

PANDIM, F. J. Proposta de um Modelo Quantitativo para Análise e Melhoria de Desempenho do Processo de S\&OP Baseado no Diagnóstico e Redução de Falhas. São Carlos. 2010. 134 f. Dissertação (Mestrado em Engenharia de Produção)- Universidade Federal de São Carlos, São Carlos, 2010.

RODRIGUES, C. M. T. et al. O modelo de referência das operações na cadeia de suprimentos - SCOR Model. In: ENCONTRO NACIONAL DE ENGENHARIA DE PRODUÇÃO, 26., 2006, Fortaleza. Anais... Fortaleza: ABEPRO, 2006.

SANTOS, R. A. B. Sales and operations planning - uma maneira simples de obter ganhos com a integração interna. Revista Tecnologística, n. 127, 2006.

SHARP, B. W. An Investigation of the factors affecting successful sales and operations planning activities in the UK. 2006. 148 f. Dissertação (Mestrado)- School of Industrial and Manufaturing Science, Cranfield University, Bedfordshire, 2006.

SHELDON, D. H. World class sales \& operations planning - a guide to successful implementation and robust execution. Lauderdale: J. Ross Publishing, 2006.

SUPPLY CHAIN COUNCIL. Supply chain operations reference model - SCOR. version 9.0. Disponível em: <https://www.supply-chain.org/>. Acesso em: dez. 2009.

TEARNAN, R. S\&OP Data Management - critical to a successful implementation. Disponível em: $<$ http://www. oliverwight-americas.com>. Acesso em: 16 dez. 2008.

TEARNAN, R., CRUM, C. Role of the S\&OP coordinator in the integrated reconciliation step of the s\&op process. Disponível em: <http://www. oliverwight-americas.com>. Acesso em: 16 dez. 2008.

WALLACE, T. F. Planejamento de Vendas e Operações - S\&OP - guia prático. São Paulo: IMAN, 2001.

WALLACE, T. F.; STAHL, R. A. Sales \& Operations Planning: the next generation. T. F. Wallace \& Co, 2005. 